\title{
Participatory Collaboration Mapping in Malawi: Making Mike's Community Informatics Idea(l)s Work
}

Aldo de Moor
CommunitySense, The Netherlands

Corresponding Author.

ademoor@communitysense.nl

\section{Introduction}

Michael "Mike" Gurstein was the founding father of the now thriving field of Community Informatics. His contributions have been numerous: his vision and passion about the field; his deep insight that it is not the technologies per se, but how they are being put to effective use that truly empowers communities; his heartfelt conviction that Community Informatics researchers and practitioners strongly depend on one another to achieve that goal; his tireless efforts, from lobbying at the highest international political levels to guiding young researchers and practitioners asking for his advice; and, of course, establishing The Journal of Community Informatics and the Community Informatics Researchers mailing list as crucial fora for the field to develop.Reflecting upon his ideas is a tall order, since his intellectual contributions, like the impacts of his work in practice, have been so many. In this personal tribute, I focus on three concepts promoted by Mike in particular that continue to inspire me in my own work: the notions of Community Informatics, Effective Use, and Community Innovation. I will illustrate how these concepts come together by applying them to a case of participatory collaboration mapping in Malawi.

DeMoor, A. (2018). Participatory Collaboration Mapping in Malawi: Making Mike's Community Informatics Idea(I)s Work. The Journal of Community Informatics, 14 (2), 109-115.

Date submitted: 2018-02-05. Date accepted: 2018-11-23.

Copyright (C), 2018 (the author as stated). Licensed under the Creative Commons AttributionNonCommercial-ShareAlike 2.5. Available at: www.ci-journal.net/index.php/ciej/article/view/1433 


\section{Inspiration: key concepts}

From the many concepts that Mike has given such rich meaning, we look at three in particular: Community Informatics, Effective Use, and Community Innovation.

\section{Community Informatics}

To Mike, Community Informatics from the beginning not only referred to the research area, but also to the practice of empowering communities with ICTs. The field occupies itself with the "deeper (community, developmental, community development, etc.) processes at work below the surface phenomena which required integration and interpretation in the context of the research but also [giving] the researchers access to a very rich set of concepts, theoretical constructs and theory overall in which to embed their analysis and understanding of what they were observing (Gurstein, 2008)". CI research, in his view, is not an isolated activity taking place in faraway, distinguished ivory towers, but is to move as much as possible from research on communities, via research for and with communities, to research by communities, ideally working towards self-empowerment (Gurstein, 2011). Key in Community Informatics is that one "[critically examines] the broader context in which the community finds itself (and including such things as externally funded projects and programs) that the community can achieve the degree of self-understanding sufficient for it to undertake effective action both in the context of specific initiatives and in larger environments". Examining this context entails "[identifying] the range of forces and interests within which the community is enclosed, allowing for successful action/implementation at the community level (ibid.)".

\section{Effective Use}

One of the crucial concepts in empowering self/context-aware communities according to Mike is Effective Use: "the capacity and opportunity to successfully integrate ICTs into the accomplishment of self or collaboratively identified goals (Gurstein, 2003)". Effective use in his view is also highly contextualized, with the focus "not simply on one of the possible 'tools' for development (access) but rather highlights the entire 'development process' including the infrastructure, hardware, software, and social organizational elements that all must be combined for development to occur" (ibid.).

\section{Community Innovation}

There are many examples of the idea of self/context-aware communities being able to effectively use ICTs to accomplish self or collaboratively identified goals. One example of particular interest in a globalizing world is Community Innovation. Mike was puzzled by the process of innovation only rarely being studied from a community perspective. This even though "so much of this type of innovation takes place within the context of communities either of place or of interest where trusted peers are enabled to experiment with established routines and practice (Gurstein, 2013)". He also considered community innovation being the intermediate level between social innovation taking place at both the local level and - through aggregation - at the regional or national level. Community innovation has "significant impacts and benefits not only for the usual effect of a 'trickle down' from elites and high performers but also a 'trickle up' from local adaptations and community-based novelty and change which, 
because it is locally based and potentially very wide-spread, can have very significant, and broadly distributed, impacts and benefits" (ibid.).

\section{Application: participatory collaboration mapping in Malawi}

Let me illustrate how strongly Mike's ideas have resonated in my own work by sharing experiences in a recent concrete case. My key $R \& D$ focus is my work on the CommunitySensor methodology for participatory community network mapping: the participatory process of capturing, visualizing, and analyzing community network relationships and applying the resulting insights to community sensemaking, building and evaluation (De Moor, 2017). In (De Moor et al., 2017; De Moor, 2018), we showed how this methodology was applied to support field building in the domain of integrating gender, nutrition, and agricultural extension (INGENAES). In that case, we used a combination of mapping and group facilitation processes to find common ground in the various projects represented by participants in the 2017 INGENAES global symposium and learning exchange on this theme (De Moor et. al, 2017). This sensemaking process resulted in a range of meaningful "seed actions" to be built on after the conference.

One of these seed actions concerned a project for kickstarting the use of participatory mapping for strengthening agricultural collaborations in Malawi. The project was a joint initiative by the Malawi-based SANE (Strengthening Agricultural and Nutrition Extension) project and the INGENAES project, both being implemented by the University of Illinois. Malawi has an extensive but complicated system of agricultural governance, called DAESS (District Agriculture Extension Services System), which aims to act as a decentralized extension framework for enabling agricultural stakeholders to enhance coordination and collaboration. It ranges from the ministerial level all the way down to the grassroots village level. The idea was to use participatory mapping of agricultural stakeholder collaborations to visualize and strengthen linkages.

To this purpose, the author and local host had first created a draft mapping language that captured the main types of elements, connections and perspectives relevant to the DAESS situation. Using this visual language, we then created a "seed map" roughly outlining the DAESS collaboration ecosystem. In country, we next trained ten Malawi agricultural extension professionals in the CommunitySensor methodology and the online network visualization tool Kumu (http://kumu.io) supporting the mapping, while simultaneously finetuning the mapping language and initial seed map with the team.

Next, we went on two site visits, working with local agricultural stakeholder representatives (farmers, business people, etc.) to have them create maps of their initiatives, projects, and programs. In particular, we were interested in having them map their own local initiatives, not primarily those driven by government or donor funding, but small-scale social innovations capturing local contexts and insights on which they themselves are the experts. First, the participants captured a number of local initiatives in various breakout groups, using an initiative mapping template. Given that there was no power in those villages, we had them create posters to represent their initiatives. The participants then presented their initiatives in the concluding plenary discussion session, making even more common sense together. Using pieces of thread, example connections between initiatives (e.g. stakeholders or resources in 
common) were symbolically represented as they were being identified in the discussion (Figure 1).

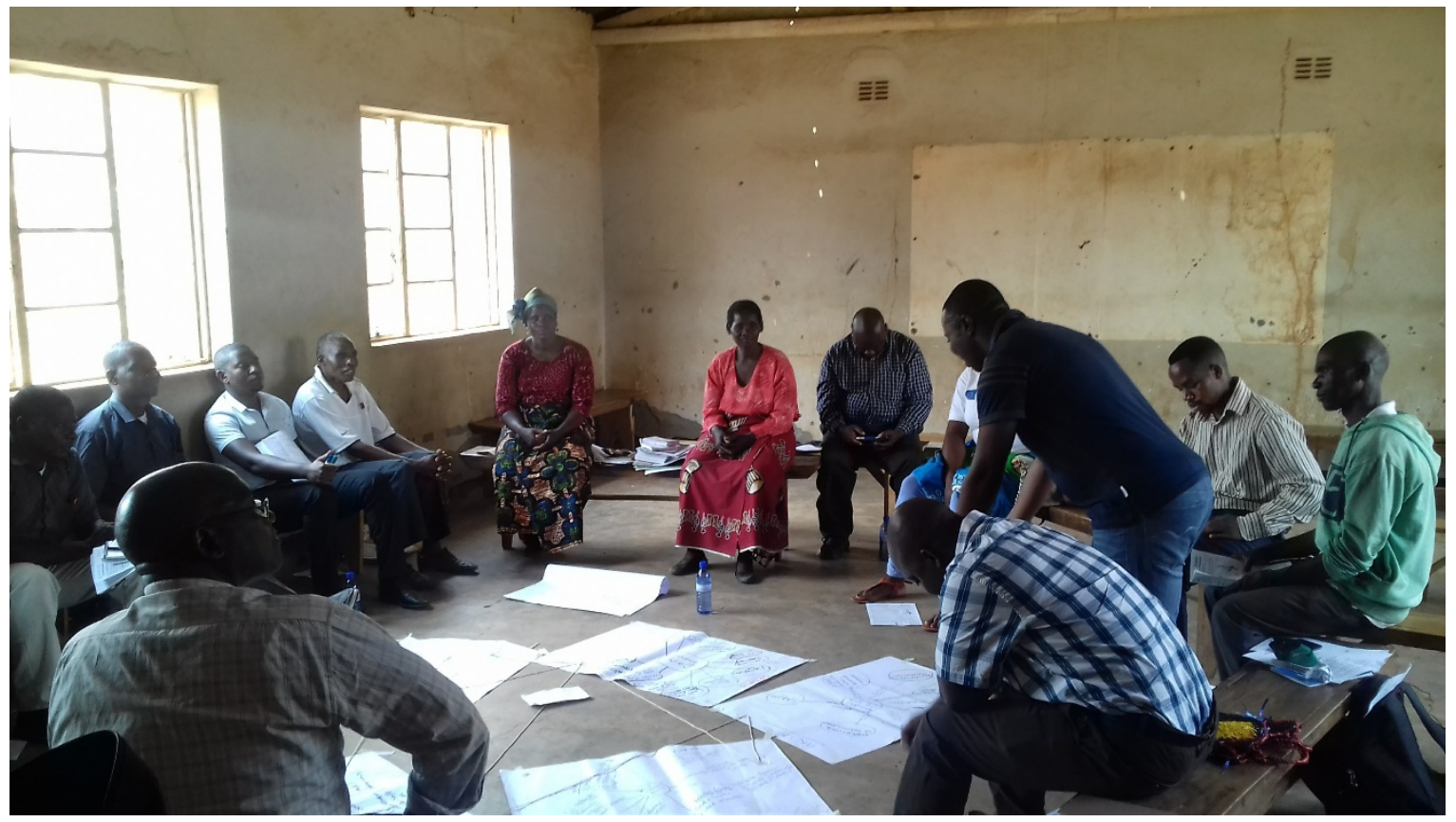

Figure 1: Making sense of farming community maps, Kalolo, Malawi, September 2017

The posters remained in the villages, as this content is owned by the community, while also allowing local community members to continue the discussion amongst themselves in between sessions with the visiting extension professionals. Afterwards, the extension professionals - course trainees but also members of agriculture coordination platforms converted photos of the posters into online Kumu maps, one per community. The online maps show otherwise hidden connections between the initiatives mapped, by automatically linking elements shared between the perspectives, such as common stakeholders (Figure 2). This is a powerful feature not possible with just the paper posters.

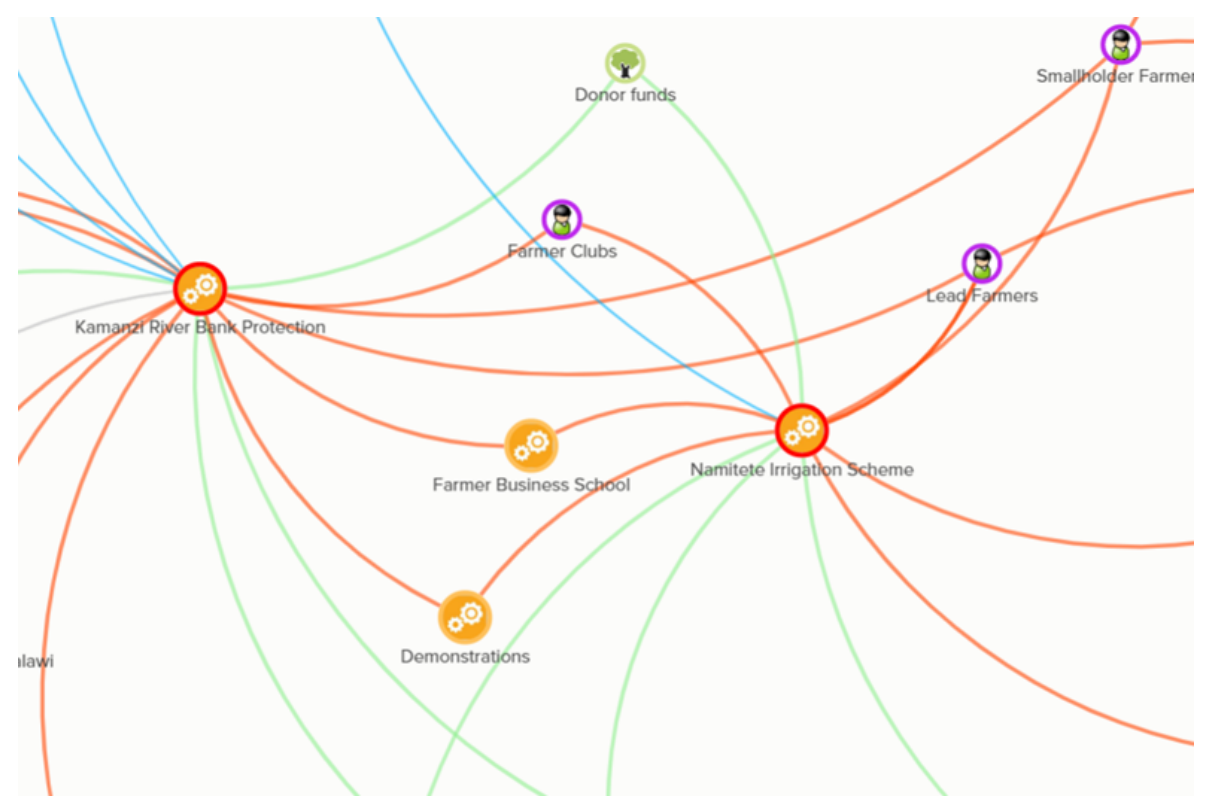

Figure 2: Identifying common ground between farming initiatives in Kalolo 
Each local agricultural community remains owner of its own online mapping project. However, these communities also continue to be supported by the agricultural coordination platforms in converting subsequent versions of the posters into electronic form and helping them to make sense of what the maps may mean and next actions to be taken. Moreover, both pilot communities reiterated their interest in the approach and willingness to continue to use it. Several follow-up mapping sessions in the pilot farming communities have already taken place. Furthermore, during a kickoff stakeholder meeting in the capital, several national organizations agreed to jointly work on expanding the participatory collaboration mapping approach, growing its applications and the stakeholders involved. Several such scaling-up sessions, making sense of the aggregate maps at the next level in the DAESS system, the district level, have already occurred.

\section{Reflection: making Community Informatics work}

When reflecting on this case through the lens of Mike's concepts, Community Informatics is at its core: participatory collaboration mapping is all about designing an ongoing, participatory research \& action process in which communities first make sense of themselves, then take effective actions towards empowerment, smartly scaling from the bottom-up. The agricultural communities creating and owning their own maps helps to promote a sense of ownership and participation. By using a common mapping language, and having the trained extension professionals convert the paper maps into an electronic version, map comparisons and linkages can be made between initiatives at the village level, but also at the higher levels. This enables stakeholders at, for instance, the district level to identify common themes or stakeholders to focus attention on in project and program development.

The Malawi participatory collaboration mapping case is also very much about Effective Use: helping to bridge the digital divide by combining low tech means (paper posters, pieces of thread) with high tech tools (online map visualization and aggregation via Kumu). The tool usage, however, is also embedded in a much larger development process, in which social organization aiming to reach collective impact takes center stage. The tweaking of this development process, taking into account all kinds of social, economic, cultural, and political constraints is really the art and science of designing the socio-technical systems that make using the tools-in-context effective.

Through mapping the context of stakeholders, activities, resources, and issues involved in otherwise seemingly isolated agricultural community initiatives, their hidden linkages are made explicit, uncovering new collaboration potentials. Community Innovation is very much driven by the joint discussion and interpretation by the local agricultural community members themselves of what these connections - or lack of them - may mean. However, it goes beyond that. By aggregating the community maps and interpreting them at the higher DAESS governance levels, ideas for new programs, funding, and policies "trickle up". This could become an important driver for "scaling collaboration smartly", matching aggregate needs identified by the local communities with resources, governance, and policy making capacity available at the higher levels. 


\section{Continuation: research ever more meets action}

According to Mike, Community Informatics as a field of research overlapping with practice matters, "because there is a need not only to do but also to systematize and to understand what is being done. In the absence of this understanding then the processes of achieving success are at best random and at worst may result in a continuous wastage of resources, time and credibility as mistakes are never learned from and so repeated, and as successes are never captured and built upon to realize further horizons (Gurstein, 2007)". What we have seen in the Malawi case, which is only one of numerous similar such Community Informaticsinspired projects, is that finding this balance between research and practice is key to making community empowerment work.

Let me conclude with Mike's call to arms, "Helping communities to understand these contexts and to explore alternative technology (and otherwise) enabled strategies to respond would seem at this juncture in history to be the highest possible calling for researchers of all kinds and including those working within the framework of Community Informatics (Gurstein, 2011)". May we all continue to heed his urgent and passionate call.

\section{Acknowledgments}

The author wishes to thank the INGENAES (Integrating Gender, Nutrition and Agricultural Extension), the AgReach SANE (Strengthening Agricultural and Nutrition Extension in Malawi) programs, for making the Malawi mapping case possible ${ }^{1}$. Without the tireless efforts by Stacia Nordin and the Malawian mapping team, our mapping project would have been far less empowering. May you continue to help make visible and "trickle up" the creative and important ideas of Malawians about improving agriculture in their country.

The Malawi mapping project was partially supported by USAID. The contents are the responsibility of the author and do not necessarily reflect the views of USAID or the United States government.

\section{References}

De Moor, A., White, N., \& Bohn, A. (2017). Using Participatory Community Network Mapping for Field Building: The INGENAES Conference Case. In Proc. of the 14th Prato CIRN Conference 25-27 October $2017 \cdot$ Monash Centre, Prato, Italy.

De Moor, A. (2017). CommunitySensor: Towards a Participatory Community Network Mapping Methodology. The Journal of Community Informatics, 13(2):35-58.

A. de Moor (2018). A Community Network Ontology for Participatory Collaboration Mapping: Towards Collective Impact, Information, 9(7): art.no.151.

Gurstein, M. (2003). Effective Use: a Community Informatics Strategy Beyond the Digital Divide. First Monday, 8(12)

Gurstein, M. (2007). What Is Community Informatics (and Why Does It Matter)? (Vol. 2). Monza, Italy: Polimetrica.

\footnotetext{
${ }^{1}$ See (De Moor, 2018) for a more detailed account of the Malawi case and full acknowledgments.
} 
Gurstein, M. (2008). Community Informatics: What's in a Name? The Journal of Community Informatics, 4(3)

Gurstein, M. (2011). Evolving Relationships: Universities, Researchers and Communities. The Journal of Community Informatics, 7(3).

Gurstein, M. (2013). Community Innovation and Community Informatics. The Journal of Community Informatics, 9(3) 